\title{
Role of androgens in survival of spermatozoa in epididymis of tammar wallaby (Macropus eugenii)
}

\author{
G. Chaturapanich, R. C. Jones and J. Clulow \\ Department of Biological Sciences, University of Newcastle, New South Wales 2308, Australia
}

\begin{abstract}
Summary. Studies of undiluted micropuncture samples of luminal fluid from the cauda epididymidis of the tammar indicated that spermatozoa are immotile in situ and spontaneously activate during collection or subsequent incubation in vitro. The suppression of sperm motility was related to the androgen status of the tammars and when this was increased by the use of Silastic implants of testosterone propionate, the spontaneous activation of samples was delayed for up to $2 \mathrm{~h}$ during incubation in vitro.

Spermatozoa survived for up to 9 weeks when isolated in the cauda epididymidis between ligatures around the ductus. However, even after isolation for 3 weeks their viability was reduced compared with samples from the contralateral, unligated duct. Isolation of a length of ductus between ligatures also reduced the concentration of spermatozoa in the lumen of the duct and reduced the concentration of some proteins in the epididymal plasma. However, it did not affect the electrophoretic pattern of detergent extracts of spermatozoa.

A study of the effects of orchidectomy and testosterone therapy indicated that sperm survival in the epididymis is androgen dependent. Orchidectomy reduced the concentration of spermatozoa in the luminal fluid and the volume of luminal fluid, and resulted in an increase in the concentration and a change in the electrophoretic pattern of protein in the fluid. The effects of orchidectomy were reduced or prevented by testosterone therapy.

It is concluded that the cauda epididymidis of the tammar is at least as well adapted for sperm storage as it is in the eutherian mammals that have been studied.
\end{abstract}

Keyw'ords: androgens; spermatozoa; tammar wallaby

\section{Introduction}

It is generally recognized that the cauda epididymidis of eutherian mammals is adapted to store spermatozoa (Glover \& Nicander, 1971; Bedford, 1979) and that the storage function is androgen dependent (Dyson \& Orgebin-Crist, 1973; Lubicz-Nawrocki \& Glover, 1973a, b; Orgebin-Crist, 1975; Lubicz-Nawrocki, 1976). For example, it has been shown, using ligatures to retain spermatozoa in the cauda epididymidis, that spermatozoa maintain their capacity to fertilize an ovum for 25 days in the mouse (Lubicz-Nawrocki et al., 1973), 21 days in the rat (White, 1932, 1933), $20-30$ days in the guinea-pig (Young, 1929), 20-25 days in the hamster (Lubicz-Nawrocki et al., 1973) and 2835 days in the rabbit (Hammond \& Asdell, 1926; Paufler \& Foote, 1968; Tesh \& Glover, 1969). In general, the motility of spermatozoa is retained for nearly twice as long as their fertilizing capacity (White, 1933; Young, 1929), and orchidectomy halves the period of survival in the epididymis.

To date, there have been no reports on the survival of spermatozoa in the epididymis of marsupials, although circumstantial evidence indicates that the cauda epididymidis is particularly well adapted for sperm storage. In the tammar, for example, the cauda epididymidis is isolated in a pocket of the tunica vaginalis which separates it from the testis. The hair covering the region is 
sparser than it is over most of the scrotum and it may be completely bald during summer (Jones, 1989). In eutherian mammals, these adaptations have been related to the maintenance of a temperature gradient between the testis and cauda epididymidis (Brooks, 1973) and are considered to favour sperm storage (Bedford, 1979).

The studies described in this report were carried out to determine the survival of spermatozoa isolated in the cauda epididymidis of the tammar and the effects of orchidectomy, and orchidectomy with testosterone therapy on sperm survival. The effects of the treatments on the occurrence of proteins in epididymal luminal plasma and detergent extracts of spermatozoa were also determined as orchidectomy has been shown to affect the secretion of epididymal proteins (Chaturapanich, 1991), but there are no data on their persistence in an isolated length of duct. As the concentration of androgens in peripheral blood of male tammars is greatly influenced by season and social factors (Caúling \& Sutherland, 1980; Inns, 1982), sperm survival was also tested in a group of intact tammars that received Silastic implants of testosterone to provide a peripheral blood concentration of testosterone sufficient to maintain a large secretory prostate gland and not suppress spermatogenesis (Jones et al., 1988; Sun et al., 1989).

\section{Materials and Methods}

\section{Animals and surgery}

Mature, male tammars weighing 6-8 kg were obtained from a colony bred at 'Gungahlin', Canberra, ACT, from a stock originally collected from Kangaroo Island, SA. During the studies they were held in yards with females (area of about $90 \mathrm{~m}^{2}$ ).

Tammars were anaesthetized by administering $4 \%$ sodium thiamyla] (Surital: Park, Davis \& Co., Ann Arbor, MI, USA) into the tail vein. They were killed by an overdose of anaesthetic.

The experiment tested six treatments (Table 1). Bilateral orchidectomy was carried out as described previously (Jones et al., 1988). Silastic implants (i.d. $3.3 \mathrm{~mm}$, o.d. $4.6 \mathrm{~mm}$; Dow Corning Corp., Midland, MI, USA) containing testosterone propionate (Sigma Chemical Co., St Louis, MO, USA), packed at a density of $4 \mathrm{mg} \mathrm{mm}^{-1}$ of tubing, were implanted under the skin above the ribs. One group of orchidectomized animals received a $35 \mathrm{~mm}$ implant per animal at the time of orchidectomy, and one group of intact animals received two $52.5 \mathrm{~mm}$ implants per animal 4 weeks before examination of epididymal samples and recovery of the prostate gland. According to an earlier study, a $35 \mathrm{~mm}$ implant maintains a peripheral blood plasma concentration of testosterone of $6 \mathrm{ng} \mathrm{ml}^{-1}$ and two $52.5 \mathrm{~mm}$ implants would maintain a testosterone concentration of $18 \mathrm{ng} \mathrm{ml}^{-1}$ (Jones et al., 1988).

Spermatozoa were isolated within the distal region of the left cauda epididymidis (region 22, Fig. 1; Jones et al., 1984) by ligating the ductus at the proximal and distal ends of the region. The testis and epididymis were exposed through a paramedial incision of the scrotum. The epididymis was viewed with an OPM 1 operating microscope (Carl Zeiss, Oberkochen, Germany) and a small incision was made in the epididymal tunic. A loop of the epididymal duct was freed from connective tissue and unravelled for a length of $4 \mathrm{~mm}$. A $3 \mathrm{~mm}$ Haemoclip (Edward Weck \& Co. Inc., Durham, North Carolina, USA) was applied across both arms of the loop formed by the duct; silk ligatures $(5 / 0$; Johnson and Johnson Medical Products, Pty Ltd, Sydney, Australia) were tied around the duct proximal and distal to the haemoclip; and the duct was cut at the apex of the loop. The epididymal tunic was sutured; the testis and epididymis were returned to the scrotum and the tunica vaginalis and scrotal skin were sutured separately.

At a time determined by the design of the experiment, samples of luminal fluid were collected from anaesthetized animals by micropuncture (Jones, 1987) of the left epididymis midway between the ligatures and at a similar location in the right epididymis. When insufficient luminal fluid could be collected by micropuncture for analyses of protein, the duct was flushed with paraffin oil and the contents collected into a haematocrit tube.

\section{Incubation of spermatozoa in vitro}

The whole droplet technique described by Pholpramool et al. (1985), which was used in a previous study of spermatozoa from the tammar (Clulow et al. 1991), was used to examine spermatozoa and incubate them in vitro for up to $8 \mathrm{~h}$ at $32^{\circ} \mathrm{C}$. Undiluted micropuncture samples $(30 \mu \mathrm{l})$ were deposited under water-saturated paraffin oil on a glass cavity microscope slide and the overall activity of the samples was scored on a scale from 0 to 10 according to the criteria described by Pholpramool et al. (1985); a zero score indicated no motility and a score of 10 was for maximum motility. The response is referred to as scores of activity (Fig. 1) to distinguish it from scores of the motility of individual spermatozoa in diluted samples (see below).

Diluted samples of spermatozoa were prepared by mincing the epididymal duct in $0.2 \mathrm{ml}$ of calcium-free KrebsRinger-phosphate (Umbreit et al., 1972) stored under water-saturated paraffin oil. The motility of spermatozoa was 


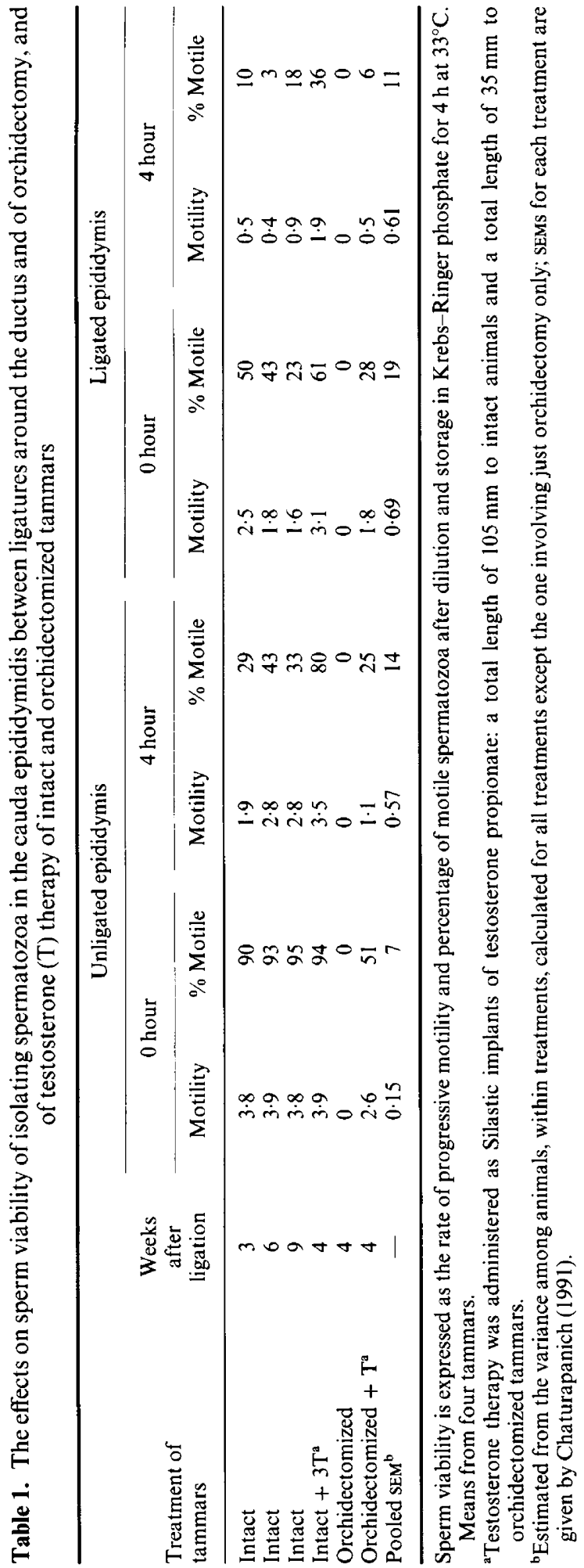




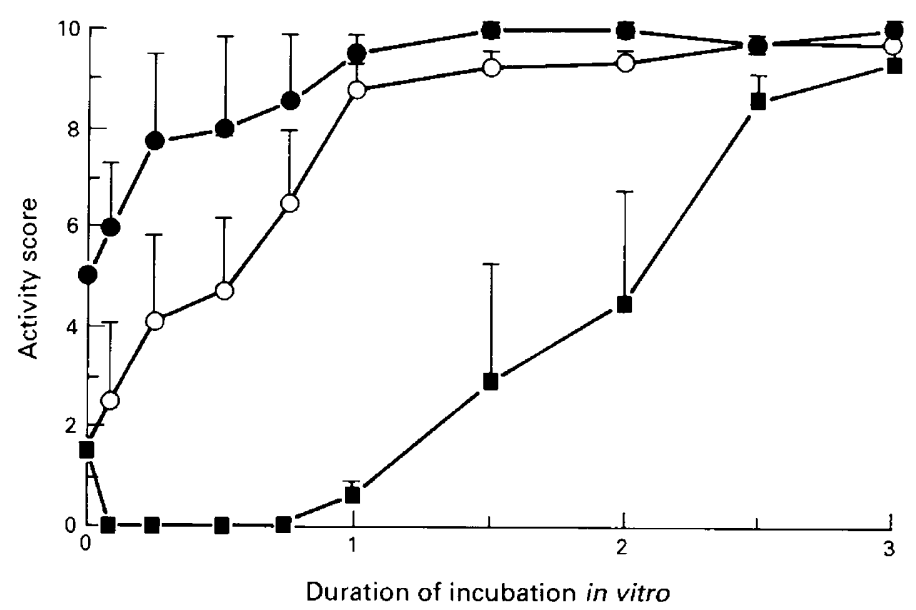

Fig. 1. Activity of spermatozoa during incubation in vitro of undiluted micropuncture samples from the unligated cauda epididymidis of three groups of intact tammars: ( $)$ animals without testosterone implants that had small nonsecretory prostates (mean \pm SEM of $11.9 \pm 2.1 \mathrm{~g}$; range $7-18 \mathrm{~g}) ;(O)$ animals without testosterone implants that had large secretory prostates (mean \pm SEM of $41 \cdot 1 \pm 13 \cdot 8 \mathrm{~g}$; range of $23-124 \mathrm{~g}$ ); ( $)$ animals that recejved two testosterone implants. They had large secretory prostates (mean \pm SEM of $73.6 \pm 8 \cdot 7 \mathrm{~g}$; range of $45-98 \mathrm{~g}$ ). Results are means \pm SEM from five, seven and four animals, respectively.

assessed in wet mounts between a microscope slide and coverslip using a phase-contrast microscope at $400 \times$ magnification. The samples were examined after incubation for $0,5,15,30,45$ and $60 \mathrm{~min}$ and then every hour for $8 \mathrm{~h}$. They were scored according to the rate of progressive motility (scale $0-4$ ) and percentage of motile spermatozoa (Table 1).

\section{Histology}

Samples of testis and epididymis were fixed in Bouin's fluid for 5 days and embedded in Paraplast (Brunswick Corp., St Louis, Missouri, USA). Sections $5 \mu \mathrm{m}$ thick were stained with haematoxylin and eosin (Humason, 1972).

\section{Assays and statistical analyses}

Spermatocrits of the micropuncture samples were determined as described previously (Jones, 1987). The concentration of protein in luminal plasma was determined using Coomassie blue (Bradford, 1976) and proteins were separated by denatured continuous gradient polyacrylamide gel electrophoresis (Jones, 1987). The interpretation of whether luminal proteins originate from blood or are androgen dependent and synthesized and secreted by the epididymal epithelium is based on work described by Chaturapanich (1991).

Means are presented with standard errors calculated from the variance between animals. Statistical analyses were performed by analyses of variance. For scores of sperm viability, the index of response for the analyses was the sum of scores made at intervals during the period of incubation (Emmens, 1947). Where appropriate the index was transformed to logarithms to make the variance homogeneous.

\section{Results}

\section{Spermatozoa from the unligated epididymis of intact tammars}

There was considerable variation among animals in scores of the activity of undiluted micropuncture samples from the unligated epididymis of animals with intact testes. Initially, the scores of activity were low (mean \pm SEM of $2.6 \pm 0.8$ for 16 animals), then progressively increased during incubation for the first $3 \mathrm{~h}$ to the maximum value scored. Maximum, or near maximum, activity was maintained during incubation of samples for $8 \mathrm{~h}$ in nine of the 16 animals examined, but was only maintained for $3-4 \mathrm{~h}$ before declining substantially in the other seven animals. 
The variation among animals in the initial activity of the epididymal samples was related to differences in their androgen status $(P<0.001)$ (Fig. 1). Samples from animals with a small nonsecretory prostate showed strong activity immediately after collection and the activity increased to about the maximum score during incubation for $1 \mathrm{~h}$. Samples from animals that had secretory prostates, but did not receive Silastic implants of testosterone, showed low activity immediately after collection. During the next $1-2 \mathrm{~h}$ the activity slowly increased to about the maximum score. All samples from animals receiving implants of testosterone were inactive, or showed only transient activity during the first $30 \mathrm{~min}$ of incubation. During the next $2.5 \mathrm{~h}$ the activity slowly increased to about the maximum score.

Spermatozoa that were diluted in Krebs-Ringer-phosphate showed no significant effect of the androgen status of the animal when sperm survival was assessed over the whole incubation period, even though the mean motility scores after incubation for $4 \mathrm{~h}$ were higher for the animals that received the Silastic implants of testosterone than for the animals that received no implants (Table 1).

\section{Effects of treatments on sperm viability}

The effects of ligation of the duct, orchidectomy, and orchidectomy and testosterone therapy are presented only for the samples of diluted spermatozoa (Table 1), as the scores of response were less variable for these samples than for the undiluted samples. For samples from the unligated duct, motility scores for the diluted samples were highest at the initial observation (about the maximum score) and started to decline after $2 \mathrm{~h}$ of incubation. Isolation of spermatozoa between ligatures resulted in a reduction in scores of rate of progressive motility and percentage motility, and the effect increased with longer periods of isolation $(P<0.01)$. For samples from the ligated epididymis of intact animals with no implants of testosterone, the proportion of animals with some motile spermatozoa was $4 / 4,2 / 4$ and $3 / 4$, respectively, for samples collected from animals 3,6 and 9 weeks after ligation. For the intact animals with testosterone implants ( 4 weeks after ligation), all samples contained motile spermatozoa.

There were no motile spermatozoa in samples taken from either the unligated or ligated epididymis 4 weeks after orchidectomy. However, testosterone administration at orchidectomy improved sperm survival.

\section{Spermatocrits}

Spermatozoa were more dilute in samples from the ligated than from the unligated epididymis of animals with intact testes $(P<0.05)$ (Table 2). The decrease in sperm concentration in the ligated duct was not due to a net increase in fluid transport into the duct since the diameter of the ligated and unligated duct was much the same.

There was very little luminal fluid in the ductus epididymidis of orchidectomized animals compared with untreated animals or orchidectomized animals that received testosterone therapy. Orchidectomy also reduced mean spermatocrit values of samples from the unligated and ligated epididymis $(P<0 \cdot 05)$. Testosterone therapy reduced the effect of orchidectomy in the unligated duct $(P<0 \cdot 05)$, but had little effect on the ligated duct.

\section{Proteins in epididymal plasma and spermatozoa}

The concentration of protein in the epididymal plasma was higher in samples from the ligated than from the unligated duct of intact animals, but the effect was not statistically significant (Table 2). Orchidectomy increased the protein concentration of epididymal plasma in the unligated and ligated ducts $(P<0.05)$, whereas testosterone therapy at orchidectomy prevented an increase in protein concentration. 
Table 2. The effects on spermatocrit values and the concentration of protein in epididymal luminal fluid of isolating spermatozoa in the cauda epididymidis between ligatures around the ductus, and orchidectomy and testosterone therapy $(\mathrm{T})$ of the tammar

\begin{tabular}{|c|c|c|c|c|c|}
\hline \multirow{2}{*}{$\begin{array}{l}\text { Treatment } \\
\text { of tammars }\end{array}$} & \multirow{2}{*}{$\begin{array}{l}\text { Weeks } \\
\text { after } \\
\text { ligation }\end{array}$} & \multicolumn{2}{|c|}{ Spermatocrit $(\%)$} & \multicolumn{2}{|c|}{ Protein concentration $\left(\mu \mathrm{g} \mu \mathrm{I}^{-1}\right)$} \\
\hline & & Unligated & Ligated & Unligated & Ligated \\
\hline Intact & 3 & $59 \cdot 2 \pm 7 \cdot 1$ & $17 \cdot 9 \pm 2.5$ & $12 \cdot 6 \pm 1 \cdot 4^{*}$ & $20 \cdot 5 \pm 4 \cdot 4^{*}$ \\
\hline Intact & 6 & $53.9 \pm 3.9$ & $23 \cdot 1 \pm 5 \cdot 2$ & $13.4 \pm 1 \cdot 0^{*}$ & $19.2 \pm 3.9^{*}$ \\
\hline Intact & 9 & $55 \cdot 4 \pm 2 \cdot 5$ & $25 \cdot 2 \pm 4 \cdot 7$ & $11 \cdot 5 \pm 3 \cdot 1$ & $14 \cdot 7 \pm 4 \cdot 7$ \\
\hline Orchidectomized & 4 & $13 \cdot 7 \pm 6 \cdot 3$ & $11.9 \pm 6.7^{*}$ & $48 \cdot 8 \pm 9 \cdot 8$ & $34 \cdot 2 \pm 8 \cdot 4$ \\
\hline Orchidectomized $+\mathrm{T}^{\mathrm{a}}$ & 4 & $27 \cdot 3 \pm 6 \cdot 2$ & $14.7 \pm 7.4$ & $9 \cdot 3 \pm 6 \cdot 3$ & $21.4 \pm 9.6$ \\
\hline
\end{tabular}

Values are means \pm SEM from four tammars.

${ }^{2}$ Testosterone therapy was administered as a $35 \mathrm{~mm}$ long Silastic implant of testosterone propionate.

${ }^{*}$ Mean \pm SEM from three tammars.

The electrophoretic pattern of epididymal plasma from the unligated epididymis was similar to that described previously (Jones, 1987; Chaturapanich, 1991). There was some variation in the effect of isolating the luminal contents between ligatures on the electrophoretic pattern of samples. In general, the main effect of the procedure was to reduce the concentration of some proteins relative to the concentration of the other proteins present, and the effect increased with the period of duct ligation. The effect was mainly on proteins from blood ( $\boldsymbol{M}_{\mathrm{r}}$ of 149000,56300 and 39800 ) and an androgen dependent protein $\left(M_{\mathrm{r}}\right.$ of 12800$)$ secreted by the caput and corpus epididymidis.

The effect of orchidectomy on the electrophoretic pattern of samples from the ligated and unligated ducts was similar. There was a reduction or loss of two androgen-dependent proteins $\left(M_{\mathrm{r}}\right.$ of 12800 and 30000 ), a loss of two blood proteins $\left(M_{\mathrm{r}}\right.$ of 82900 and 90600$)$, and an increase in the relative amounts of three blood proteins $\left(M_{\mathrm{r}}\right.$ of 39800,56300 and 71700$)$. Testosterone therapy prevented the changes in electrophoretic pattern.

Duct ligation or orchidectomy had no effect on polyacrylamide gels of detergent extracts of spermatozoa.

\section{Epididymal structure}

Before fixation, the tunic over the ligated cauda epididymidis was more opaque than over the contralateral epididymis.

Only the histological effects of ligating the ductus epididymidis of animals with intact testes were examined as the effects of orchidectomy, and orchidectomy and testosterone therapy have already been reported (Jones et al., 1988). The ligated cauda epididymidis contained granuloma in the intertubular tissue proximal to the distal ligature and near the proximal ligature. The granuloma contained numerous spermatozoa and leucocytes.

Overall, the epithelia lining the ligated and unligated ducts were histologically similar, except for one animal examined 6 weeks after ligation. The epithelium in this animal had adopted a stratified appearance and in some sections there were some degenerating epithelial cells in the lumen. There was also an invasion of leucocytes into the epididymal lumen of two animals examined 9 weeks after ligation. However, viability scores for the spermatozoa from these animals were within the range of values for samples from other animals with the same treatment.

\section{Discussion}

The studies described in this report suggest that the cauda epididymidis of the tammar is as well adapted for the storage of spermatozoa as the cauda epididymidis of the eutherian mammals that have been studied. Proximal and distal ligatures were used around the ductus epididymidis in this 
study, whereas most studies on eutherians used a single ligature around the ductus deferens or ductus epididymidis. In rabbits (Paufler \& Foote, 1968), a second ligature reduces sperm survival to one third of that achieved with a single ligature.

Although this study showed that sperm survival in the cauda epididymidis of the tammar is androgen dependent, spermatozoa sampled from the unligated epididymis of animals of low androgen status (prostate mass of 7-18 g) survived dilution and incubation as well as spermatozoa from other animals. This finding is consistent with our knowledge that, although there is considerable seasonal variation in androgen levels in the male tammar (Inns, 1982), spermatogenesis (Inns, 1982) and the viability of epididymal spermatozoa (author's unpublished observations) remain constant throughout the year. This may be because androgens are concentrated in the cauda epididymidis via a luminal route of transport as in the rat (Turner et al., 1984; Turner, 1988). It is also known that the caput and corpus epididymidis of the tammar converts testosterone to dihydrotestosterone (Jones et al., 1988), a more potent androgen for sperm storage than testosterone (Lubicz-Nawrocki, 1973, 1976). However, more work on the tammar is required to resolve the importance of luminal androgens as their concentration will depend on the luminal concentration of proteins that bind androgens (Turner \& Roddy, 1990).

The collection of immotile spermatozoa from the epididymis has been achieved in only five mammals besides the tammar: the rat (Wyker \& Howard, 1977; Turner \& Reich, 1985), guinea-pig (Turner \& Reich, 1985), boar (Dacheux \& Paquignon, 1980), bull (Carr \& Acott, 1984) and African elephant (Jones, 1973). However, the tammar is the only animal in which undiluted epididymal spermatozoa spontaneously develop motility after incubation in vitro (Clulow et al. 1991) and this is the first report to show that suppression of sperm activity in vivo may be related to the androgen status of an animal. The extended period of suppression achieved with testosterone implants has been confirmed in subsequent studies of five animals. Nevertheless, more work is required on the factors affecting sperm motility and the role of androgens in regulating the activity of the epididymal mucosa.

The studies described in this report indicate that granuloma develop in the intertubular tissue within three weeks of ligating the ductus epididymidis. As this is a much shorter period than occurs following vasectomy of other species (5-8 weeks in the hamster and rhesus monkey and 32 weeks in the rabbit; Bedford, 1976) it is possible that the ductus epididymidis in the tammar releases its contents into the intertubular tissue more readily than in the other species that have been studied. This conclusion is consistent with an earlier observation ( $R$. C. Jones, unpublished) that efferent duct ligation in the tammar is usually followed by rupture of the ducts proximal to the ligature.

Loss of epididymal spermatozoa has not been described in ligation studies of eutherian mammals that are not androgen deficient (Lubicz-Nawrocki, 1974; Jones \& Glover, 1975). The loss in the tammar was probably due to the rupture of the duct as discussed above and as suggested by Temple-Smith \& Bedford (1978) for the androgen-deficient animal. It is possible that some spermatozoa may have been phagocytosed by the epididymal mucosa, but we saw no histological evidence for this. It was also considered that the loss of spermatozoa was not due to their redistribution in the ductus, as samples collected by flushing the ductus had about the same spermatocrit values as micropuncture samples. The loss of epididymal spermatozoa following orchidectomy of the tammar is in agreement with work on the hamster (Lubicz-Nawrocki, 1974) and rabbit (Jones \& Glover, 1975; Jones \& Dott, 1980).

The increase in concentration of luminal protein after orchidectomy of the tammar is probably due to a reduction in fluid transport into the duct rather than an increase in rate of protein secretion, since Wong \& Yeung (1977) have shown that fluid transport is androgen dependent and we have not found a large increase in protein synthesis after orchidectomy (Chaturapanich, 1991).

The loss of proteins with an $M_{\mathrm{r}}$ of 30000 and 12800 from the luminal fluids after orchidectomy is consistent with our earlier findings that their secretion is androgen dependent (Chaturapanich, 1991). Failure to detect reductions in other androgen-dependent proteins secreted by the epididymis of the tammar probably occurs because silver staining is not as sensitive a technique as 
fluorography (Chaturapanich, 1991). The increase in concentrations of some proteins $\left(M_{\mathrm{r}}\right.$ of 71700,56300 and 39800 ) that have the same $M_{\mathrm{r}}$ as proteins in blood is consistent with findings in rabbits (Jones \& Dott, 1980). However, the treatment also caused a decrease in intraluminal concentrations of two proteins that are considered to originate from blood $\left(M_{\mathrm{r}}\right.$ of 82900 and 90600 ; Chaturapanich, 1991).

This work was supported by a grant from the Australian Research Council.

\section{References}

Bedford, J.M. (1976) Adaptations of the male reproductive tract and the fate of spermatozoa following vasectomy in the rabbit, rhesus monkey, hamster and rat. Biology of Reproduction 14, 118-142.

Bedford, J.M. (1979) Evolution of the sperm maturation and sperm storage function of the epididymis. In The Spermatozoon Maturation, Motility, Surface Properties and Comparative Aspects, pp. 7-21. Eds D. W. Fawcett \& J. M. Bedford. Urban \& Schwarzenberg, Inc., Baltimore-Munich.

Bradford, M.M. (1976) A rapid and sensitive method for the quantitation of microgram quantities of protein utilizing the principle of protein-dye binding. Analytical Biochemistry 72, 248-254.

Brooks, D.E. (1973) Epididymal and testicular temperature in the unrestrained conscious rat. Journal of Reproduction and Fertility 35, 157-160.

Carr, D.W. \& Acott, T.S. (1984) Inhibition of bovine spermatozoa by caudal epididymal fluid: I. Studies of a sperm motility quiescence factor. Biology of Reproduction 30, 913-925.

Catling, P.C. \& Sutherland, R.L. (1980) Effect of gonadectomy, season and the presence of females on plasma testosterone, luteinizing hormone and follicle stimulating hormone levels in male tammar wallabies (Macropus eugenii). Journal of Endocrinology 86, 25-33.

Chaturapanich, G. (1991) Epididymal function in the tammar, Macropus eugenii, with particular emphasis on protein secretion. PhD thesis, University of Newcastle, Australia.

Clulow, J., Jones, R.C. \& Murdoch, R.N. (1992) Maturation and regulation of the motility of spermatozoa in the epididymis of the tammar wallaby, Macropus eugenii. Journal of Reproduction and Fertility 94, 295-303.

Dacheux, J-L. \& Paquignon, M. (1980) Relationship between the fertilizing ability, motility and metabolism of epididymal spermatozoa. Reproduction Nutrition Development 20, 1085-1099.

Dyson, A.L.M.B. \& Orgebin-Crist, M.C. (1973) Effect of hypophysectomy, castration and androgen replacement upon the fertilizing ability of rat epididymal spermatozoa. Endocrinology 93, 391-402.

Emmens, C.W. (1947) The motility and viability of rabbit spermatozoa at different hydrogen ion concentrations. Journal of Physiology 106, 471-481.

Glover, T.D. \& Nicander, L. (1971) Some aspects of structure and function in the mammalian epididymis. Journal of Reproduction and Fertility Supplement 13, 39- 50.
Hammond J. \& Asdell, S.A. (1926) The vitality of the spermatozoa in the male and female reproductive tracts. British Journal of Experimental Biology 4, 155-185.

Humason, G.L. (1972) Animal Tissue Techniques. W. H. Freeman and Company, San Francisco.

Inns, R. W. (1982) Seasonal changes in the accessory reproductive system and testosterone levels in the male tammar wallaby, Macropus eugenii, in the wild. Journal of Reproduction and Fertility 66, 675-680.

Jones, R. \& Dott, H.M. (1980) Changes in luminal plasma and disappearance of spermatozoa from the ligated cauda epididymidis of the androgen-deficient rabbit. Journal of Reproduction and Fertility 60 , $65-72$.

Jones, R. \& Glover, T.D. (1975) Interrelationships between spermatozoa, the epididymis and epididymal plasma. In The Biology of the Male Gamete, pp. 367-384. Eds J. G. Duckett \& P. A. Racey. Academic Press, London.

Jones, R.C. (1973) Collection, motility and storage of spermatozoa from the African elephant, Loxodonta africana. Nature 243, 38-39.

Jones, R.C. (1987) Changes in protein composition of the luminal fluids along the epididymis of the tammar, Macropus eugenii. Journal of Reproduction and Fertility 80, 193-199.

Jones, R.C. (1989) Reproduction in male Macropodidae. In Kangaroos, wallabies and rat kangaroos, pp. 287 305. Eds G. Grigg, P. Jarman \& I. Hume. Surrey Beatty \& Sons Pty Ltd.

Jones, R.C., Hinds, L.A. \& Tyndale-Biscoe, C.H. (1984) Ultrastructure of the epididymis of the tammar, Macropus eugenii, and its relationship to sperm maturation. Cell and Tissue Research 237, 525-535.

Jones, R.C., Stone, G.M., Hinds, L.A. \& Setchell, B.P. (1988) Distribution of $5 \alpha$-reductase in the epididymis of the tammar wallaby (Macropus eugenii) and dependence of the epididymis on systemic testosterone and luminal fluids from the testis. Journal of Reproduction and Fertility 83, 779-783.

Lubicz-Nawrocki, C.M. (1973) Anomalous effects of progesterone on the maturation and survival of spermatozoa in the epididymis of the golden hamster. Journal of Endocrinology 58, 199-204.

Lubicz-Nawrocki, C.M. (1974) Effects of castration and testosterone replacement on the number of spermatozoa in the cauda epididymidis of hamsters. Journal of Reproduction and Fertility 39, 97-100.

Lubicz-Nawrocki, C.M. (1976) The effects of metabolites of testosterone on the development of fertilizing 
ability by spermatozoa in the epididymis of castrated hamsters. Journal of Experimental Zoology 197, $89-96$.

Lubicz-Nawrocki, C.M. \& Glover, T.D. (1973a) The effects of hypophysectomy and the paradoxical effect of human chorionic gonadotrophin on the viability of hamster spermatozoa. Journal of Endocrinology 58, 177-184.

Lubicz-Nawrocki, C.M. \& Glover, T.D. (1973b) The influence of the testis on the survival of spermatozoa in the epididymis of the golden hamster, Mesocricetus auratus. Journal of Reproduction and Fertility 34, 315-329.

Lubicz-Nawrocki, C.M., Lau, N.I.F. \& Chang, M.C. (1973) The fertilizing life of spermatozoa in the cauda epididymidis of mice and hamsters. Journal of Reproduction and Fertility 35, 165-168.

Orgebin-Crist, M-C. (1975) Endocrine control of the development and maintenance of sperm fertilizing ability in the epididymis. In Handbook of Physiology, (Vol. 5), pp. 319-338. Eds D. W. Hamilton \& R. O. Greep. American Physiology Society, Washington.

Paufler, S.K. \& Foote, R.H. (1968) Morphology, motility and fertility of spermatozoa recovered from different areas of ligated rabbit epididymides. Journal of Reproduction and Fertility 17, 125-137.

Pholpramool, C., Zupp, J.L. \& Setchell, B.P. (1985) Motility of undiluted bull epididymal spermatozoa collected by micropuncture. Journal of Reproduction and Fertility 75, 413-420.

Sun, Y.T., Irby, D.C., Robertson, D.M. \& de Kretser, D.M. (1989) The effects of exogenously administered testosterone on spermatogenesis in intact and hypophysectomized rats. Endocrinology 125, 10001010.

Temple-Smith, P.D. \& Bedford, J.M. (1978) Fate of spermatozoa in the male: II. Absence of a specific sperm disposal mechanism in the androgen deficient hamster and rabbit. Biology of Reproduction 18, 791-798.

Tesh, J.M. \& Glover, T.D. (1969) Ageing of rabbit spermatozoa in the male tract and its effect on fertility. Journal of Reproduction and Fertility 20, 287-297.

Turner, T. (1988) Transepithelial movement of ${ }^{3} \mathrm{H}$ androgen in seminiferous and epididymal tubules: a study using in vivo micropuncture and in vivo microperfusion. Biology of Reproduction 39, 399-408.

Turner, T.T. \& Reich, G.W. (1985) Cauda epididymal sperm motility: a comparison among five species. Biology of Reproduction 32, $120-128$.

Turner, T.T. \& Roody, M.S. (1990) Intraluminal androgen binding protein alters ${ }^{3} \mathrm{H}$-androgen uptake by rat epididymal tubules in vitro. Biology of Reproduction 43, 414419 .

Turner, T.T., Jones, C.E., Howards, S.S., Ewing, L.L., Zegeye, B. \& Gunsalus, G.L. (1984) On the androgen microenvironment of maturing spermatozoa. Endocrinology 115, 1925-1932.

Umbreit, W.W., Burris, R.H. \& Stauffer, J.F. (1972) Manometric and Biochemical Techniques. 5th edn, p. 146. Burgess Publishing Co., Minneapolis.

White, W.E. (1932) The effect of hypophysectomy on the survival of spermatozoa in the male rat. Anatomical Record 54, 253-271.

White, W.E. (1933) The duration of fertility and the histological changes in the reproductive organs after ligation of the vasa efferentia in the rat. Proceedings of Royal Society of London Series B 113, 544-550.

Wong, P.Y.D. \& Yeung, C.H. (1977) Hormonal regulation of fluid reabsorption in isolated rat cauda epididymidis. Endocrinology 101, 1391-1397.

Wyker, R. \& Howards, S.S. (1977) Micropuncture studies of the motility of rete testis and epididymal spermatozoa. Fertility and Sterility 28, 108-112.

Young, W.C. (1929) A study of the function of the epididymis. II. The importance of an ageing process in sperm for the length of the period during which fertilizing capacity is retained by sperm isolated in the epididymis of the guinea-pig. Journal of Morphology and Physiology 48, 475-491.

Received 26 March 1991 